\title{
As Metas de Inflação: Sugestões para um Regime Permanente*
}

\author{
Inflation Targeting: Proposals for a Permanent Regime
}

\author{
FABIO GIAMBIAGI** \\ JOSÉ CARLOS CARVALHO***
}

\begin{abstract}
RESUMO: Em 1999, o regime de metas de inflação foi introduzido no Brasil em um ambiente com muitas incertezas e taxas de inflação relativamente altas. Como consequência, o conjunto de regras que até hoje regem o regime brasileiro ainda carece de um forte apoio institucional. Este artigo faz algumas propostas para um regime permanente de metas de inflação. Ao fazê-lo, discutimos como um maior comprometimento institucional pode ser alcançado com a configuração da meta de inflação. Também discutimos questões sobre qual deve ser o nível da meta permanente de inflação e também quanto pode ser tolerado de desvio. Com base nessas questões, sugerimos um conjunto de regras a serem adotadas no Brasil.
\end{abstract}

PALAVRAS CHAVE: Política monetária; inflação; Metas de inflação.

ABSTRACT: In 1999 the inflation targeting regime was introduced in Brazil in an environment plenty of uncertainties and relatively high inflation rates. As a consequence, the set of rules that to this day govern the Brazilian regime still lack a strong institutional support. This paper makes some proposals for a permanent inflation targeting regime. In doing so, we discuss how can a greater institutional commitment be achieved with the inflation targeting setup. We also discuss issues on what the permanent inflation target level should be and also how much deviation from the target should be tolerated. Based on these issues, we suggest a set of rules to be adopted in Brazil.

KEYWORDS: Monetary policy; inflation; inflation targets.

JEL Classification: E52; E58.

\footnotetext{
* Os autores agradecem os comentários de Ana Cláudia Além, Armando Castelar Pinheiro e de dois pareceristas anônimos. Como é de praxe, a responsabilidade pelo conteúdo do texto cabe exclusivamente aos autores.

* * Economista do BNDES, Rio de Janeiro/RJ, Brasil. E-mail: fgiambia@bndes.gov.br; Orcid: 0000-00027698-2587.

\#** Economista do IGP Asset Management, Rio de Janeiro/RJ, Brasil. E-mail: jcarlos@paineirasinvestimentos.com.br; Orcid: 0000-0002-4382-3889.
} 


\section{INTRODUÇÃO}

O regime de metas de inflação é uma das alternativas que as autoridades de um país têm para seguir em termos de política monetária e que incluem os enfoques baseados em: a) âncoras cambiais, como na Argentina; b) metas monetárias, como na Alemanha antes do euro; ou c) metas de inflação implícitas, como muitos entendem que seja o regime de política monetária dos EUA (Mishkin, 1999).

No caso brasileiro, o regime de metas de inflação (inflation target) adotado em 1999 passou com sucesso pelo teste inicial. Em 1999, em que pese o fato de que a taxa de inflação oficial $(8,9 \%)$ do Índice de Preços ao Consumidor Ampliado (IPCA) do IBGE tenha sido ligeiramente superior à meta, ela se situou dentro do intervalo de tolerância admitido pelo Banco Central (BC), e a inflação anual, em termos de preços ao consumidor, foi muito inferior ao que inicialmente se temia, no contexto da mega-desvalorização ocorrida durante o primeiro trimestre do ano. Em 2000 ficou na meta de 6\%.

As condições em que essa experiência institucional se iniciou no Brasil estiveram muito longe do ideal. Nas palavras explicitadas com surpreendente franqueza pelo próprio presidente do BC, Armínio Fraga, "nós não tínhamos, naquele momento, a menor idéia de qual seria o nível razoável [da taxa de inflação]" (Fraga, 2000, pág.2). A nova modalidade de operação da política monetária, que substituiu o papel de "âncora" desempenhado pela taxa de câmbio, surgiu então em condições marcadas por: i) uma súbita mudança de preços relativos; ii) uma alta acentuada da inflação; iii) a ausência de um Departamento de Pesquisa forte no âmbito do BC; iv) a falta de séries estatísticas longas em condições econômicas de estabilidade para fazer testes econométricos robustos; e v) o temor de que o Brasil repetisse a experiência do México, onde a desvalorização de 1994/1995 acarretou uma inflação anual de mais de $50 \%$.

Da mesma forma que o Chile, depois de muitos anos de inflation target definiu uma "banda" de meta inflacionária de 2 a 4\%, o Brasil, após diminuir a inflação de quase $9 \%$ em 1999, para - provavelmente - um nível da ordem de 4\% em 2002, quando o próximo Governo se iniciar, poderá vir a adotar uma sinalização similar, definindo regras duradouras para o comportamento das autoridades monetárias. A motivação deste artigo é alimentar o debate em torno do assunto, procurando responder a questões tais como: qual deve ser a meta de longo prazo a ser perseguida?; qual deve ser o intervalo de variação aceito?; etc.

O artigo está dividido em 6 seções. Depois desta breve introdução, o texto apresenta a lógica da adoção do regime de metas de inflação e, na seção seguinte, comenta as características deste sistema no Brasil. $\mathrm{Na}$ seção 4, tecem-se alguns comentários acerca da importância da constituição de um sistema de regras de funcionamento da política econômica, como base para a consolidação da estabilidade. A quinta seção representa o coração do artigo e nela são expostas e justificadas uma série de sugestões acerca de quais deveriam ser as características desse regime permanente de metas de inflação, em termos de relacionamento entre Exe- 
cutivo e Congresso Nacional; o nível da meta de inflação; e outros elementos importantes a considerar. Por último, sintetizam-se as conclusões do trabalho.

\section{A LÓGICA DAS METAS DE INFLAÇÃO}

O tema das metas de inflação começou a ser discutido com certa intensidade nos meios acadêmicos internacionais a partir do início dos anos 90 , na seqüência da adoção dessa modalidade de política antiinflacionária por parte do primeiro grupo de países da lista de aproximadamente uma dezena de nações que atualmente incorporaram o inflation target às suas respectivas políticas econômicas. ${ }^{1}$

Como frisam Leiderman e Svensson, na introdução ao livro por eles editado a respeito das experiências nacionais de adoção de metas de inflação até meados dos anos 90, este sistema tem, basicamente, duas grandes funções (Leiderman e Svensson, 1995). Em primeiro lugar, ele serve como elemento de coordenação de expectativas para os agentes econômicos em geral e, particularmente, para o mercado financeiro. E, em segundo lugar, opera como um guia de plena transparência para a condução da política monetária: os resultados desta política passam a ser "bons" ou "ruins" em função da aderência ou não da inflação às metas previamente fixadas e não em função do cumprimento de metas monetárias a) de significado pouco claro; b) difíceis de seguir à risca; e c) que, mesmo cumpridas, não garantiriam necessariamente o êxito de uma política antiinflacionária. A nova política implica uma maior accountability do Governo em geral e das autoridades econômicas em particular.

Refletindo sobre o tipo de dificuldades com as quais se defrontaram as autoridades monetárias perseguindo metas de $\mathrm{M} 1, \mathrm{M} 2$, etc. ao longo das décadas e o progressivo ceticismo acerca da eficácia das metas monetárias como instrumento de combate à inflação, Alan Blinder, em seu conhecido ensaio sobre a "arte" de ser um banqueiro central, cita a frase de Gerry Bouey, então governador do Banco do Canadá, quem reagindo à crítica pelo fato de o Banco Central desse país ter deixado de lado o controle estrito da moeda, declarou que "nós não abandonamos os agregados monetários; eles é que nos abandonaram" (citado em Blinder, 1998, página 28). Decorre daí o sentimento de que o controle monetário stricto sensu teria deixado de exercer a mesma influência que há algumas décadas - antes das inovações financeiras que marcaram os últimos 30 ou 40 anos - como fator determinante da dinâmica da inflação. Vale destacar que este sentimento atingiu a quase todos os países — incluindo os industrializados — e não apenas aqueles com uma história de inflação elevada.

\footnotetext{
${ }^{1}$ Para uma defesa das metas de inflação vis-à-vis outras alternativas de combate à inflação, ver, entre outros, o livro clássico com a coletânea de Leiderman e Svensson (1995) e Svensson (1998). Para uma discussão geral das características do regime de inflation targeting, ver Agénor (2000). Na literatura brasileira, para um levantamento das referências sobre o tema, ver Giambiagi e Rigolon (1999). Para uma análise sobre as experiências de inflation target em economias emergentes, ver Mishkin (2000).
} 
O reconhecimento dessas dificuldades alimentou em muitos países a popularidade da âncora cambial como alternativa de política antiinflacionária ${ }^{2}$. O benefício deste mecanismo para esse fim, especialmente no curto prazo, foi testado diversas vezes, com êxito. Entretanto, a teoria também sugere que esse tipo de mecanismos implica uma série de problemas de médio e longo prazos, ligados i) à maior dificuldade dos países de se ajustarem frente a problemas externos; ii) ao impacto sobre a política monetária, pela necessidade, que uma taxa de câmbio rígida pode implicar, de se praticarem taxas de juros elevadas na defesa da política cambial; e iii) à vulnerabilidade frente a ataques especulativos. Os problemas observados para conservar as paridades cambiais na crise do sistema monetário europeu de 1992 - com a saída provisória, entre outros, da libra, do mecanismo da "serpente" - e as sucessivas crises - e desvalorizações — que ocorreram durante 1997/1999 em diversas economias emergentes, na seqüência da crise do Sudeste asiático de 1997, mostraram que os problemas apontados pela teoria estavam se verificando na prática e reduziram muito o apelo das políticas de câmbio fixo ou semi-fixo. Como já tinha sido salientado anteriormente por Barry Eichengreen, "the trend toward greater exchange rate flexibility is an inevitable consequence of rising international capital mobility" (Eichengreen, 1996, página 191).

Face aos problemas acumulados com as tentativas de controle monetário e conhecidos os ônus da ancoragem cambial, a opção pelo sistema de metas de inflação tornou-se uma conseqüência natural da frustração com as demais alternativas de política monetária. A dúvida é se é mais recomendável perseguir metas não anunciadas de inflação ou fazer isso de modo explícito. A primeira alternativa tem a vantagem, do ponto de vista das autoridades, de não limitar muito a sua margem de manobra. No velho dilema entre regras e discrecionalidade, representa o reconhecimento das vantagens desta última e de não se prender a uma estratégia específica, sem prejuízo de se perseguirem certos objetivos não anunciados em longo prazo, arte essa que Alan Greenspan tem exercitado nos últimos anos com rara maestria. ${ }^{3}$ Entretanto, como salienta Mishkin (1999), a estratégia de "cumprimento sem explicitação" ou " just do it", sem a institucionalização do sistema de metas, além de ser pouco transparente, torna o êxito da política de combate à alta de preços excessivamente dependente da habilidade e do comprometimento (commitment) das autoridades da época em lidar com as pressões inflacionárias, sem oferecer, portanto, garantias de continuidade do êxito da estratégia, em caso de mudança de nomes por ocasião da troca de comando no Banco Central.

\footnotetext{
${ }^{2}$ A popularidade da âncora cambial em certos momentos da história de muitos países, decorreu também do fato de que ela permitia conciliar o combate à inflação com o crescimento econômico, pelo menos durante algum tempo. Existia a percepção de que para debelar processos crônicos de alta inflação, a restrição monetária, levada ao extremo, teria que ser profundamente recessiva.

${ }^{3}$ Cabe citar aqui, a propósito destas questões, as palavras carregadas de ironia pronunciadas por Martin Schürz, economista do Banco Nacional da Áustria, em um seminário a respeito do funcionamento dos Bancos Centrais, há alguns anos: "Secrecy is a way of a Central Bank to seem smart, because it does not define targets that could be wrong".
} 
Em função desse tipo de considerações, diversos países seguiram nos anos 90 políticas de combate à inflação baseadas na adoção de inflation targets. Resumidamente, tal sistema

- permite que a política monetária se concentre na busca prioritária de um certonível de inflação; e

- possibilita uma avaliação clara do desempenho da política monetária, atra-vés da comparação entre a meta e a inflação observada;

O sistema em questão se baseia na definição de uma meta explícita para a variação dos preços por parte das autoridades e na atribuição de uma responsabilidade formal ao Banco Central pelo alcance do resultado desejado. De um modo geral, a experiência internacional desde que a modalidade foi adotada em diversos países foi bastante positiva, sendo acompanhada por uma queda da inflação em relação aos níveis iniciais e por uma estabilização da mesma em níveis baixos, uma vez atingido o objetivo de convergência com a inflação dos países mais avançados.

\section{AS METAS DE INFLAÇÃO NO BRASIL ${ }^{4}$}

O sistema de metas de inflação foi mencionado pela primeira vez no Brasil oficialmente em março de 1999, logo depois da posse do novo presidente do Banco Central, Armínio Fraga e no contexto de uma grave crise cambial, com alta acelerada da taxa de câmbio e temores de uma retomada do processo de inflação elevada. Nesse ambiente de grande incerteza, as autoridades anunciaram que até o final de junho seriam divulgadas as características do novo regime e se tomaram quatro meses para aguardar a evolução dos acontecimentos, dada a enorme disparidade existente na época em relação à expectativa futura de inflação. ${ }^{5}$ Em junho, após a apreciação nominal da taxa de câmbio, já com o ambiente mais calmo e com as expectativas de inflação muito menores, foram então anunciadas as metas para 1999, 2000 e 2001, anteriormente citadas. ${ }^{6}$

$\mathrm{Na}$ ocasião, o Banco Central anunciou também os seguintes pontos:

a) a meta de inflação seria uma meta do Governo e não do Banco Central,implicando um grau importante de comprometimento oficial com o objetivo numérico definido;

b) até 2001 haveria um intervalo de tolerância para as variações da taxa

\footnotetext{
${ }^{4}$ Para uma explicação oficial das principais características do modelo de metas de inflação adotado no Brasil, ver Werlang, Bogdanski e Tombini (2000). Para um debate acerca dos resultados iniciais do novo sistema, ver Pastore e Pinotti (2000) e a coletânea de textos do Banco Central (2000).

${ }^{5}$ Cabe lembrar que na ocasião chegou até a haver bancos internacionais prevendo que a inflação brasileira de 1999 poderia atingir $80 \%$.

${ }^{6}$ A taxa de câmbio R\$/US\$, que antes da desvalorização, em janeiro de 1999, era de R \$1,21, chegou a ser de $\mathrm{R}$ \$ 2,16 nos primeiros dias de março, caindo posteriormente até $\mathrm{R} \$ 1,66$ no final de abril e ficando em torno de $\mathrm{R} \$ 1,70 / 1,80$ nos dias do anúncio do novo sistema, em junho.
} 
deinflação, na forma de 2 pontos percentuais para cima e para baixo em relação ao centro da banda, implicando que a meta de $8,0 \%$ de 1999 estaria sujeita a um piso de $6,0 \%$ e a um teto de $10,0 \%$, valendo a mesma lógica para os dois anos seguintes; ${ }^{7}$

c) o índice de preços escolhido como "termômetro" de inflação seria o IPCA, calculado pelo IBGE;

d) a meta seria definida em relação ao índice de preços "cheio", sem qualquer tipo de expurgo para definir um índice "núcleo" (core inflation);

e) as metas anunciadas não estariam sujeita a revisões ou ajustes posteriores;

f) todos os meses de junho de cada ano t, mantidas as metas para os anos $t$ e $(t+1)$, o Governo divulgaria a meta de inflação para o ano $(t+2)$; e

g) o Banco Central começaria a divulgar, como de fato fez, poucos meses de-pois, os chamados "Relatórios de inflação", de periodicidade trimestral, com informações macroeconômicas; a justificativa para as medidas adotadas visando o cumprimento da meta; e as projeções nas quais a instituição se baseou para a sua tomada de decisões.

Paralelamente, o Banco Central criou um Departamento de Pesquisas, com o fim de, entre outras coisas, elaborar estudos úteis para a análise da trajetória e das previsões da taxa de inflação; e investiu no treinamento de pessoal e na geração de modelos econométricos de cálculo da taxa de inflação como função de uma série de variáveis. Ao mesmo tempo, foram criadas duas instâncias de comunicação entre o Banco Central e o público. De um lado, aquele passou a coletar sistematicamente informações referentes a previsões feitas pelo mercado financeiro e por analistas independentes acerca do comportamento da própria inflação. De outro, passou a se comunicar regularmente com o mercado através da divulgação de informações consideradas relevantes sobre temas econômicos, na forma de pequenas notas informativas de 2 a 3 páginas, distribuídas a um mailing list de mais de 3000 economistas, operadores do mercado financiero, jornalistas e formadores de opinião.

O novo modelo enfrentou um primeiro teste importante poucos meses depois de ser anunciado. Embora o fato de a taxa de inflação ter fechado o ano de 1999 em níveis de apenas um dígito tenha sido comemorado, muitos analistas consideraram que a alta das taxas mensais no final do ano e o conseqüente desvio em relação à meta foram resultado do que eles julgavam que teria sido uma redução excessivamente rápida das taxas de juros a partir de abril de $1999 .{ }^{8}$ Nesse contexto e com uma evidente preocupação em dar sinais claros de que o Governo estava firmemente empenhado em garantir o cumprimento da meta de $6,0 \%$ do ano seguinte, o Banco Central deteve a trajetória de queda da taxa de juros overnight (SELIC), que entre setembro de 1999 e março de 2000 ficou estável em 19,0\%, após o quê, em março de 2000, as taxas tiveram apenas uma pequena queda, para

\footnotetext{
${ }^{7} \mathrm{O}$ intervalo foi mantido inalterado quando um ano depois foi anunciada a meta para 2002.

${ }^{8}$ A taxa de juros tinha sido elevada para $45 \%$ em março de 99.
} 
$18,5 \%$, só voltando a cair mais acentuadamente em junho daquele ano. ${ }^{9}$ Esse comportamento da autoridade monetária foi decisivo para assegurar a queda da taxa de inflação em 2000, apesar da influência negativa do choque do petróleo, particularmente intensa no caso brasileiro (Gráfico 1). ${ }^{10}$

Gráfico 1: IPCA - 12 meses (\%)

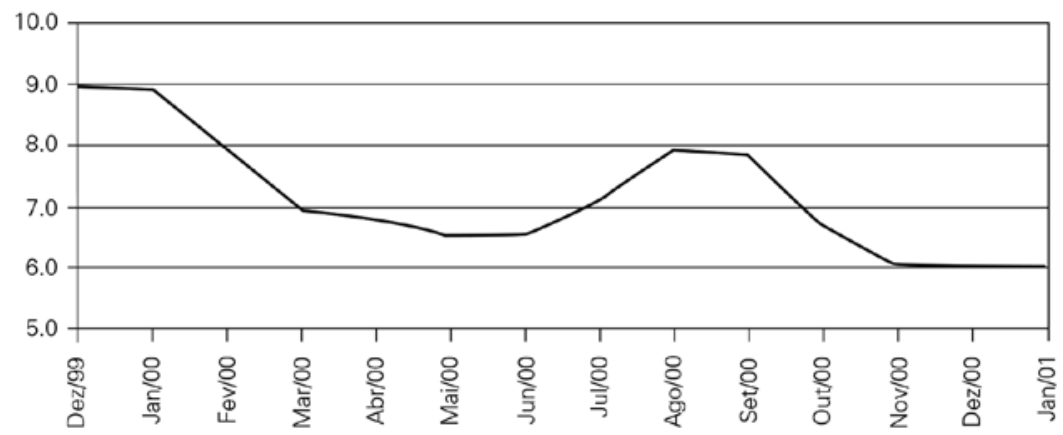

\section{A INSTITUCIONALIZAÇÃO DA ESTABILIDADE ${ }^{11}$}

O Brasil tem tomado algumas iniciativas, ao longo dos últimos dois anos, destinadas a consolidar o esforço de estabilização iniciado com o Plano Real e reforçado com as medidas de ajuste de 1999. Entre elas, a própria adoção das metas de inflação; a aprovação da Lei de Responsabilidade Fiscal; e a reafirmação da lógica da política econômica, através do anúncio da meta fiscal de 2002 - que vai além do acordo com o FMI previsto para acabar no final de 2001 — são indicações de que as atuais autoridades concebem a estabilização como algo que deve ser duradouro no tempo e ter continuidade ao longo dos anos.

O objetivo desse conjunto de iniciativas é, de alguma forma e na medida do possível, tentar isolar a direção da economia dos rumos da política do país, no sentido de consolidar certas práticas - especialmente o controle fiscal e a procura de uma baixa taxa de variação dos preços - como políticas de Estado e não mais como políticas de governos específicos. Evitando mudanças drásticas de rumo no futuro, o país seguiria os caminhos da maior parte dos países industrializados e das economias emergentes mais bem-sucedidas, nas quais, mesmo na presença de al-

\footnotetext{
${ }^{9}$ Com isso, a média das expectativas de inflação para 2000, apurada no levantamento do Banco Central, caiu de aproximadamente $7,0 \%$ no início do ano, para $6,0 \%$ - ou seja, para a meta - em junho, quando o Banco Central retomou a trajetória de queda dos juros.

${ }^{10}$ Ao longo de 2001, porém, a incidência negativa de sucessivos choques exógenos (crise argentina, estagnação dos países centrais, etc.) sobre a cotação do dólar levou a um aumento da inflação em 12 meses no primeiro semestre do ano.

${ }^{11}$ Algumas das questões aqui discutidas se assemelham com as que são tratadas por Worrell (2000) para o contexto específico de pequenas economias abertas.
} 
ternância de poder, há um conjunto de compromissos associados à política monetária e à prática de uma gestão fiscal austera, que tendem a ser mantidos, independentemente de quem estiver no governo.

Tendo essas preocupações como pano de fundo, poderia ser contemplada a adoção de um conjunto de regras referentes às metas de inflação, porém de caráter "permanente". Dizemos aqui "permanente", porque dificilmente esse tipo de regras duram para sempre. Por exemplo, uma taxa de inflação como a dos EUA há 10 anos, da ordem de $5 \%$, seria considerada baixa no Brasil à época. Em 2002, no contexto de uma inflação nos EUA de 3\%, entretanto, $5 \%$ seria uma taxa relativamente alta.

De qualquer forma, o que se deseja frisar aqui é a conveniência de definir regras que não dependam da discrecionalidade das autoridades da época. Quando o regime de metas inflacionárias foi adotado no Brasil, com uma taxa de inflação anual de quase $10 \%$ e o propósito de convergir com a inflação internacional, era preciso, por definição de convergência, adotar metas para o ano $(t+1)$ que fossem inferiores às do ano $t \mathrm{e}$ fazer a cada ano anúncios que pudessem ser diferentes dos do ano anterior. Uma vez que a economia se aproxima dos níveis de inflação internacional, porém, passa a fazer sentido que se anunciem regras fixas, no sentido de valerem por tempo indefinido. Uma possibilidade de mudança de regras ocorreria, por exemplo, se os próprios parâmetros de inflação internacional se modificassem em relação aos atuais e daqui a cinco anos ou mais, a inflação dos EUA e da Europa fosse muito diferente da atual, mas de qualquer forma essa mudança não ocorreria no curto prazo. Nossa proposta é que, a partir de determinado ponto, as autoridades brasileiras anunciem um conjunto de propostas que representem objetivos duradouros da política de metas inflacionárias, a serem perseguidos por tempo indefinido, como ocorre atualmente, por exemplo, no caso do Chile.

\section{RUMO A REGRAS PERMANENTES: PROPOSTAS PARA DEBATE}

Com base nesse espírito, são feitas a seguir uma série de sugestões visando o estabelecimento desse conjunto de regras. As sugestões foram divididas em dois blocos: a) aquelas referentes a questões institucionais; e b) as que tratam de questões estritamente técnicas.

\subsection{Questões institucionais}

O primeiro tipo de questões refere-se ao relacionamento entre os Poderes Executivo e Judiciário e aos poderes do presidente do Banco Central.

\subsubsection{Aprovação pelo Congresso}

Os EUA e a Alemanha antes do euro constituíam os casos paradigmáticos de independência do Banco Central. Mesmo nos EUA, entretanto, conforme frisado 
inclusive pelos próprios defensores dessa independência, esta aplica-se aos instrumentos e não aos objetivos da instituição. Em outra palavras, a sociedade, de alguma forma, permite que certas decisões caibam a um corpo técnico especializado que entende-se que zele adequadamente pelo cumprimento de certos objetivos de interesse do país, os quais, contudo, são definidos pelos representantes escolhidos diretamente pela sociedade - ou seja, os parlamentares. Como reconhecido por um ex-integrante do board do FED, o professor Alan Blinder, no seu livro já citado, "the bank's basic goals are chosen by elected politicians, not by unelected technocrats" (Blinder, 1998, p. 67).

O Congresso brasileiro tem recusado até agora conceder independência ao Banco Central, pelo temor a que este venha a se converter em uma espécie de "quarto Poder" e tire poderes que o Legislativo considera que sejam prerrogativa exclusiva dele ou do Poder Executivo. Uma possibilidade que caberia analisar, intermediária entre a situação atual - que combina a falta de independência do Banco Central, com a falta de qualquer influência do Poder Legislativo na definição da meta de inflação - e a defesa da independência plena do Banco Central que costuma ser feita por parte dos economistas, consistiria em aprofundar a sugestão de Delfim Netto (1999): "Em alguns países, e essa não parece ser uma má idéia, a tarefa do Banco Central é estipulada por um contrato entre ele e o Ministério da Fazenda ou o Congresso Nacional, no qual se compromete, por escrito, com a meta inflacionária negociada e com os requisitos necessários para atingi-la, e explica, também por escrito, os eventuais desvios e o tempo que julga conveniente e necessário para recuperá-la" (Delfim Netto, 1999, p. 382).

Nesse caso, poder-se-ia pensar em um esquema por meio do qual a meta de inflação fosse proposta pelo ministro da Fazenda, mas sancionada, por exemplo, por meio de Resolução do Senado Federal, o que converteria a regra a ser adotada em um compromisso institucional do país como um todo, com força de Lei e não em um objetivo de um governo específico - e que pode mudar ao sabor das circunstâncias. Em troca, o Congresso aprovaria legislação específica concedendo a necessária independência ao Banco Central para o cumprimento desses objetivos, sob o compromisso de o presidente do Banco Central se reportar regularmente semestral ou anualmente - ao Congresso, para fazer um balanço da política antiinflacionária e apresentar a visão da instituição, em moldes similares aos ritos que o presidente do FED tem que obedecer nos EUA quando comparece às sessões de comissões específicas no Congresso desse país.

\subsubsection{A possibilidade de demissão do presidente do BC}

Um dos problemas principais associados ao cumprimento de regras em economia diz respeito aos mecanismos que obriguem ao cumprimento (enforcement) dessas regras e estabeleçam formas de punição em caso de violação da regra.

Entre os países que adotam metas formais de inflação, a Nova Zelândia é o único que tem uma regra clara, similar a um contrato, prevendo punição à auto- 
ridade monetária se a meta de inflação não for cumprida, na forma de destituição do presidente do Banco Central. Há algumas razões que justificam a ambigüidade de ter uma meta que supostamente vale como uma regra, sem que se prevejam alternativas no caso de a regra não ser respeitada. O risco de introduzir um componente de instabilidade; a perda de reputação que adviria para o presidente destituído; a eventual injustiça de punir autoridades monetárias por desvios causados por problemas de origem fiscal; etc., são alguns dos temores que explicam a referida lacuna.

Por outro lado, como a existência de uma sanção de fato tornaria as metas de inflação ainda mais críveis e facilitaria a obtenção de um mandato por parte do

Congresso para que as autoridades monetárias se concentrassem nesse objetivo, tendo independência operacional e mandatos fixos, a hipótese de uma sanção merece ser explorada.

Uma possibilidade que poderia ser examinada é a de que a possível sanção, na forma de demissão do presidente do Banco Central, fique condicionada a certas regras mais flexíveis do que a simples destituição em caso de desrespeito da meta, só ocorrendo em caso de descumprimento do limite superior de inflação por dois anos consecutivos.

Isso preservaria a lógica das metas de inflação, ao mesmo tempo em que aumentaria o comprometimento (commitment) das autoridades com o cumprimento das metas e viabilizaria a permanência dessas autoridades se, após um eventual desvio além do compreendido no intervalo da banda, a trajetória da inflação voltasse a convergir na direção da meta.

\subsection{Questões técnicas}

Cabe agora analisar algumas questões técnicas a respeito das quais seria conveniente refletir na definição de um conjunto de regras permanente do regime de metas de inflação. São elas: o nível da meta; o intervalo da banda; e o conceito de índice de preços a ser utilizado.

\subsubsection{O nível da meta}

Talvez a questão mais importante a ser definida ao se estabelecerem as características de um regime de metas permanentes de inflação seja o nível da meta. Por um lado, a meta de $2002(3,5 \%)$ parece ser ainda relativamente elevada vis-à-vis o que se considera inflação baixa nas economias avançadas. Por outro lado, não existem praticamente países com históricos de estabilidade plena de preços — isto é, inflação zero - por um período muito prolongado. ${ }^{12}$ Portanto, é válido, nos parece, aceitar

\footnotetext{
${ }^{12}$ Como frisou recentemente a revista The Economist, insuspeita de simpatias populistas, "na verdade ninguém sabe o que poderia ser uma taxa ótima. Todos os dirigentes de bancos centrais concordam em que a estabilidade de preços deve ser o principal objetivo da política monetária. Mas o que significa exatamente estabilidade de preços?" (reproduzido em suplemento do Jornal Valor, 14/11/2000, p. 8).
} 
a proposição de que uma meta de inflação duradoura deveria ser algo entre 1 e $3 \%$ a.a. A questão é: que nível escolher nesse intervalo de possibilidades?

Para isso, há que se levar em consideração uma série de elementos, particularmente:

- nível da taxa de inflação nos EUA — índices "cheio" e de core inflation;

- a taxa de inflação recente em outros países industrializados;

- a expectativa de inflação nessas áreas econômicas para o futuro; e

- nível da taxa definida como alvo nos países que adotam regimes de inflation target.

Nesse sentido, é útil observar os dados do Gráfico 2. Ele mostra a evolução da taxa de variação da média anual do índice de preços ao consumidor (Consumer Index of Prices - CPI) nos EUA, a partir de 1991. Há dois dados que nos parece particularmente relevante destacar, pois são úteis para a reflexão que se avizinha no Brasil sobre que taxa mirar como alvo a política de longo prazo do Banco Central: a) antes do choque do petróleo de 2000, o último ano no qual a inflação média tinha sido superior a 3,0\% nos EUA fôra há 10 anos, em 1991, quando atingiu 4,2\%; e b) a taxa de variação média anual do CPI dos EUA nos últimos 5 anos até 2000 foi de $2,5 \%$ a.a. Essas informações são complementadas pela Tabela 1 e pelo Gráfico 3.

A Tabela 1 mostra a evolução da variação do núcleo ou core do CPI dos EUA. A taxa de variação deste índice na média dos 5 anos do período 1996/2000 foi de $2,4 \%$ a.a., similar à do índice "cheio". A inclusão do índice no elenco de dados aqui apresentados, porém, justifica-se pelo que tem acontecido recentemente em função da alta dos preços do petróleo, que tem feito a taxa de variação do IPC em 12 meses atingir valores próximos de $4 \%$ em alguns meses do ano 2000 . O Gráfico 3 mostra, contudo, que essa pressão de alta não tem contaminado com tanta intensidade o core em 12 meses, que de um modo geral nos últimos quatro anos tem se conservado sempre abaixo de $2,5 \%$.

Nos demais países industrializados, deixando de lado o caso do Japão, abalado por uma longa e profunda depressão com impactos deflacionários intensos, a situação tem sido bastante heterogênea, com o destaque em termos de baixa inflação, pela sua importância econômica, cabendo à Alemanha, que apresentou uma variação média do seu Índice de Preços ao Consumidor (IPC) de apenas 1,1\% a.a. nos últimos 5 anos completados em 2000. 
Gráfico 2

CPI - EUA - Médias anuais (\%)

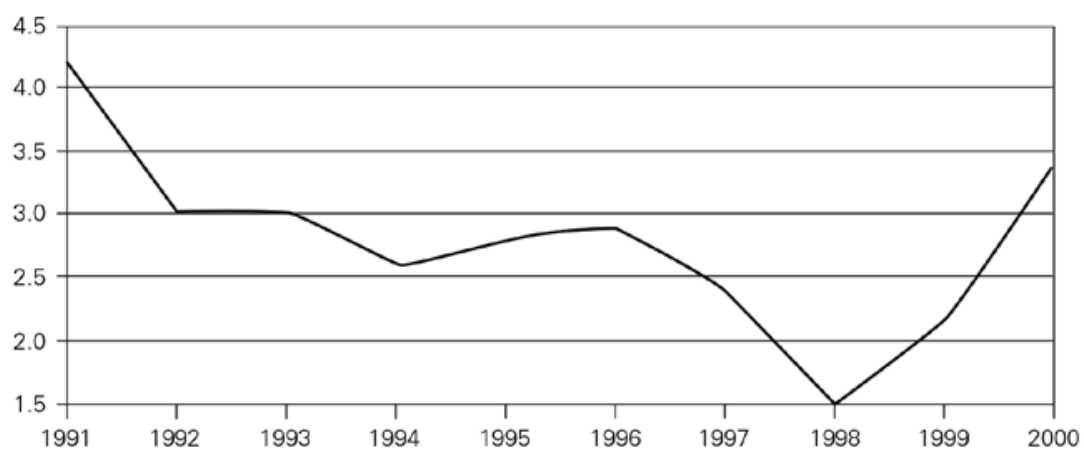

Gráfico 3

CPI - EUA - Core inflation - 12 meses (\%)

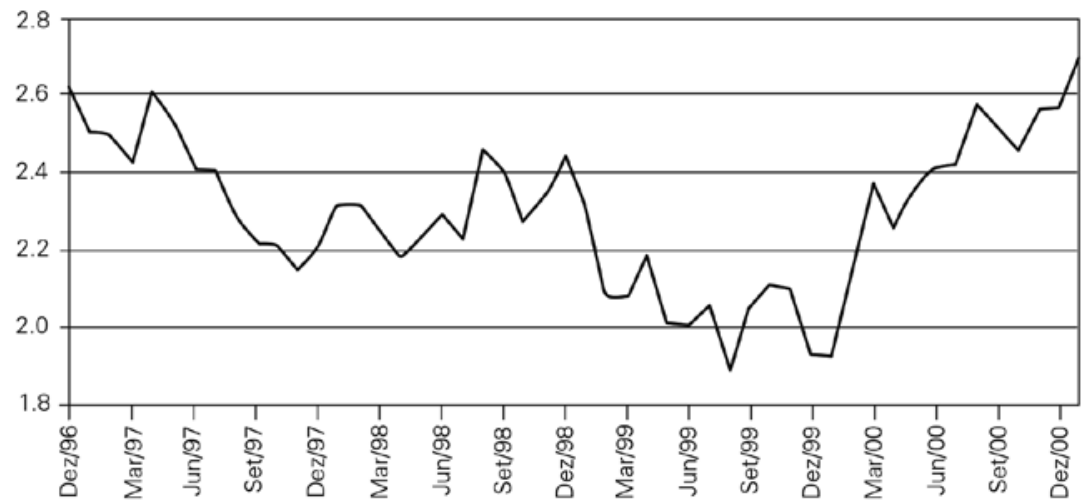

Tabela 1: CPI - EUA - Core inflation - Janeiro/Dezembro (\%)

\begin{tabular}{cc}
\hline Ano & Inflação \\
\hline 1991 & 4,4 \\
1992 & 3,4 \\
1993 & 3,1 \\
1994 & 2,7 \\
1995 & 3,0 \\
1996 & 2,6 \\
1997 & 2,2 \\
1998 & 2,5 \\
1999 & 1,9 \\
2000 & 2,6 \\
2001 & 2,6 (janeiro 2001) \\
\end{tabular}


É preciso também levar em consideração a expectativa imediata de variação dos preços para 2001, que tem sido extremamente baixa, de menos de $2 \%$ para a média dos países industrializados, em função da menor pressão esperada dos preços do petróleo na economia dos EUA e da continuidade da estabilidade de preços no Japão (Tabela 2).

Tabela 2: Previsões de inflação (\%)

\begin{tabular}{lcc}
\hline Países & 2000 & 2001 \\
\hline Países industrializados & 2,2 & 1,5 \\
EUA & 3,2 & 1,7 \\
Japão & $-0,3$ & 0,0 \\
Zona do euro & 1,9 & 1,7 \\
$\quad$ França & 1,3 & 1,3 \\
$\quad$ Alemanha & 1,6 & 1,5 \\
$\quad$ Itália & 2,3 & 2,0 \\
$\quad$ Espanha & 2,8 & 2,4 \\
Reino Unido & 2,4 & 2,1 \\
Canadá & 2,4 & 2,1 \\
\hline
\end{tabular}

Fonte: Dornbusch (2000), com base em dados do Economist Consensus Forecast.

No que tange às taxas de variação anual dos preços, que balizam o comportamento das autoridades monetárias nos países que adotam formalmente regimes de metas de inflação, a média se situa entre 2,0 e 2,5\% (Tabela 3).

Por último, deve ser lembrado que o Banco Central Europeu (BCE) opera subordinado a um constraint representado pelo fato de que o teto de inflação "aceitável” para a instituição - isto é, que não induz esta a adotar uma política monetária reativa - é de 2,0\%. Embora o BCE não opere com o conceito de "meta", considerando que a inflação apresenta algumas flutuações, se a meta for rigorosamente respeitada ao longo dos anos, cabe imaginar que a média de inflação dos países da "zona do euro", no futuro, deverá ser provavelmente de $1 \%$ a $2 \%$ a.a. ${ }^{13}$

À luz do que foi apresentado, a conclusão que se pode extrair é que uma taxa de inflação de 3,0\% pareceria ser ainda bastante elevada, como meta duradoura, no atual contexto mundial. No caso do Brasil, mesmo que a curto prazo uma inflação de 3,0\% represente um grande avanço, em um cenário de previsão de estabilidade da taxa de câmbio real e nominal, a meta de inflação deveria ser o mais próxima possível da variação dos preços dos países com economias estáveis - ou seja, inferior a $3,0 \%$.

\footnotetext{
${ }^{13} \mathrm{Em} 2000$, contudo, apesar do referido teto, a inflação da zona do euro foi de 2,8\%. Isso, porém, levou o BCE a elevar as taxas de juros ao longo do ano.
} 
Tabela 3: Características das metas de inflação em países selecionados

\begin{tabular}{lccc}
\hline \multicolumn{1}{c}{ País } & $\begin{array}{c}\text { Ponto central } \\
\text { meta inflação }(\%)\end{array}$ & $\begin{array}{c}\text { Intervalo acima ou abaixo } \\
\text { de ponto central }( \pm, \%)\end{array}$ & $\begin{array}{c}\text { Expurgo } \\
\text { IPC }\end{array}$ \\
\hline Nova Zelândia & 1,5 & 1,5 & Sim \\
Canadá & 2,0 & 1,0 & Sim \\
Reino Unido & 2,5 & 1,0 & Sim \\
Suécia & 2,0 & 1,0 & Não \\
Finlândia & 2,0 & Não há explicitação de bandas & Sim \\
Austrália & 2,5 & 0,5 & Sim \\
Espanha & 2,0 (teto) & - & Não \\
Chile & 3,0 & 1,0 & Não \\
\hline
\end{tabular}

Fontes: SPE (1999), Conjuntura Econômica (2000).

\subsubsection{O intervalo da banda}

Como enfatizado por Clifton (1999), em um regime de metas de inflação visto como permanente, as autoridades devem ter muito cuidado em se fazer entender em relação ao significado por elas atribuído ao piso da banda. É preciso esclarecer se nesse tipo de regime a autoridade monetária vai atuar diante da ameaça de a banda ser "furada" no intervalo inferior, com o mesmo vigor com que se entende que deve atuar se há uma ameaça concreta de o teto da banda ser ultrapassado. Ao mesmo tempo, o tema é importante para definir se a meta de inflação corresponde ou não ao conceito de ponto médio da banda - isto é, à média entre piso e teto. Uma intervalo entre 0 e $3 \%$ de inflação, por exemplo, pode ser consistente tanto com uma meta de $1,5 \%$, como com uma de $2,0 \%$ e diferenças assimétricas entre os extremos da banda e a meta. Estes são, de qualquer forma, detalhes de debates próprios de países onde a estabilidade está bastante enraizada e passará algum tempo antes de que em nosso país cheguemos ao ponto de discutir esse tipo de minúcias.

O que é relevante definir, no Brasil, é se o intervalo de tolerância de 2 pontos percentuais acima e abaixo da meta se mantém ou não no nível atual e, no caso de diminuir, até que ponto isso deve ser feito. Como sabemos, o Brasil definiu esse intervalo relativamente amplo vis-à-vis a experiência internacional em função de duas considerações. A primeira, o elevado nível da meta inicial - 8,0\% em 1999. E o segundo, o fato de que se optou por trabalhar com um índice cheio ao invés de ter uma meta associada ao conceito de núcleo de inflação ou core. ${ }^{14}$

Nesse sentido, é útil observar novamente a Tabela 3. Ela mostra que há uma certa tendência a que o intervalo em relação à meta seja de 1 ponto percentual

\footnotetext{
${ }^{14}$ Cabe lembrar, entretanto, que no contexto da convergencia macroeconômica do Mercosul, os países do bloco acordaram recentemente adotar um "core" a partir de 2006.
} 
acima ou abaixo dela. Por outro lado, dos oito países da Tabela, em cinco deles o IPC adotado como referência é o core.

Isso sugere uma alternativa salomônica a ser seguida pelo Brasil. Partimos do duplo pressuposto de que: a) é razoável que o intervalo da banda, para uma meta de inflação da ordem de 3,0\% ou menos, deva ser inferior ao que se tinha no começo do sistema, quando a meta foi de $8,0 \%$, mas, ao mesmo tempo, b) é igualmente razoável que se entenda que, com as pressões que existem no Brasil, exista uma tolerância ligeiramente maior com a inflação em relação à que se verifica em países com longa tradição de estabilidade. Existe portanto uma possibilidade intermediária entre a experiência brasileira atual de ter intervalos de 2 pontos percentuais acima e abaixo de uma meta e a experiência internacional, que aponta para um intervalo de 1 ponto percentual acima e abaixo da meta. Essa alternativa consistiria em diminuir o intervalo de variação para 1,5 ponto percentuais acima e abaixo da meta do núcleo de inflação.

A rationale do 1,5 ponto de amplitude para a banda pode ainda ser justificada pelo intervalo de confiança da volatilidade do IPCA. Qual é a lógica de existir uma banda de confiança? Na verdade, como existe um componente estocástico na inflação acumulada em 12 meses, pode ser que se observe um valor mais elevado na inflação sem que isso represente de fato um desvio do target de inflação - i.e., o desvio pode ser atribuído apenas à volatilidade da inflação. Dessa forma, o Gráfico 4 mostra que o desvio-padrão da inflação acumulada no IPCA em 12 meses, atingiu $0,7 \%$ nos 12 meses terminados em janeiro de 2001. Portanto, uma banda de confiança de 2 desvios-padrão seria equivalente a 1,4\%. Isso significa que, se observarmos um desvio do centro da meta superior a 1,5\%, poderíamos inferir um forte indício de que esse desvio foi além do componente aleatório e que o Banco Central está de fato se afastando do target projetado. É importante notar que estamos utilizando o IPCA cheio e portanto esta amplitude da banda já incorpora espaço para acomodar os choques não relacionados ao core inflation.

Gráfico 4

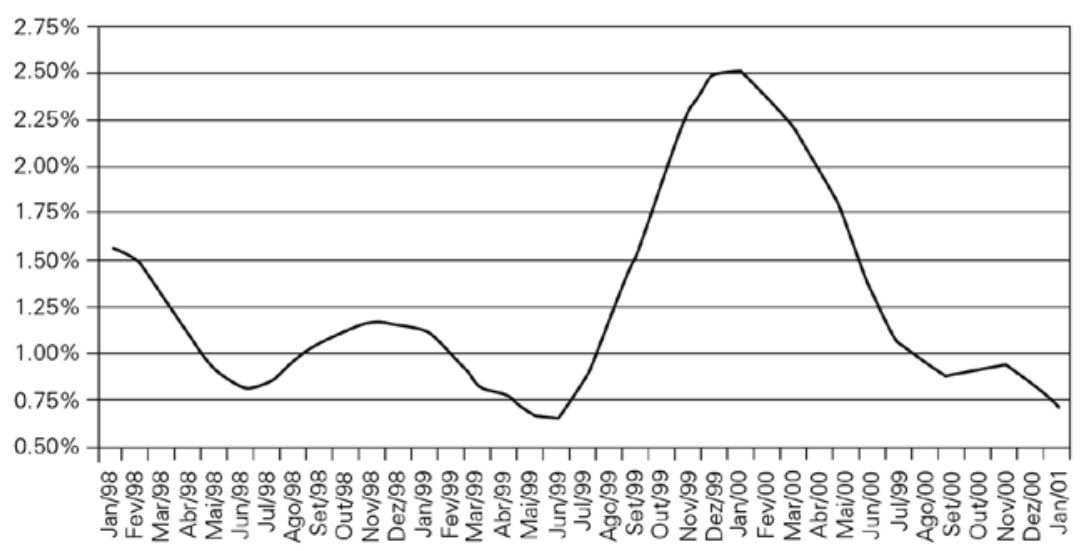

Fonte: IBGE, elaboração própria. 


\subsubsection{O uso do IPCA médio e a periodicidade do target}

Uma alternativa de flexibilização para aceitar desvios temporários em relação à meta pode ser a de utilizar a inflação de períodos mais longos. Os benefícios deste tipo de medida são evidentes. Uma menor volatilidade no target da inflação teoricamente gera uma menor necessidade de reação do governo e portanto uma menor volatilidade do produto e do emprego. Essa medida, no entanto, pode ter prejuízos que não são intuitivos como veremos a seguir. Nesse caso, porém, é crucial evitar que essa flexibilidade se traduza em decisões sistematicamente equivocadas das autoridades monetárias. Vejamos isso mais de perto.

Suponhamos que o nível de inflação em um dado período de tempo $(P t)$ seja uma função do hiato do produto da economia $(h t)$, da taxa de câmbio (et), do equilíbrio entre a oferta e demanda por moeda sintetizados na taxa de juros (it) e ainda de fatores exógenos $(A t)$, como por exemplo o preço das commodities e ganhos de produtividade. Dessa forma temos:

$$
P_{t}=P\left(A_{t}, h_{t}, e_{t}, i_{t}\right)
$$

Podemos então definir a função do inflation targeting, i.e., a função de reação do Banco Central, como:

$$
i_{t}=P^{-1}\left(P_{t} \mid A_{t}, h_{t}, e_{t}\right)
$$

Ou seja, a função $P^{-1}$ define uma função de reação do Banco Central que permite escolher uma taxa de juros $i$ tendo observado uma inflação em um dado período $P$. Intuitivamente, podemos adotar como target médias mais longas de $P_{t}$. Em teoria isso permitiria menor necessidade de reagir a flutuações em $P$, gerando menos volatilidade no produto.

Nesse ponto cabe a seguinte pergunta. Será que é sempre verdade que adotando um período maior de médias a variância deverá ser menor? Como exemplo, vamos considerar o caso de dois períodos. Ou seja, ao invés do Banco Central reagir à inflação acumulada em um ano, a sua função reação é determinada pela inflação média de dois anos. A noção intuitiva que temos é que ao utilizar a média de dois anos, a variância deste novo target tende a ser menor e portanto o Banco Central pode ter reações menos bruscas. Dada a função de reação do Banco Central, isso implica também em menos flutuações indesejáveis do produto.

Esse raciocínio, apesar de intuitivo, nem sempre é correto. Na verdade estamos querendo comparar:

$$
\underset{\text { com }}{\operatorname{Var}\left[\frac{P_{i}+P_{j}}{2}\right]}
$$

$\operatorname{Var}\left(P_{i}\right)$ 
Desdobrando o primeiro termo, temos:

$$
\begin{aligned}
& \operatorname{Var}\left[\frac{P_{i}+P_{j}}{2}\right]=\operatorname{Var}\left[\frac{P_{i}}{2}\right]+\operatorname{Var}\left[\frac{P_{j}}{2}\right]+2 \cdot \operatorname{Cov}\left[\frac{P_{i}}{2}, \frac{P_{j}}{2}\right]= \\
& =\frac{1}{4} \cdot \operatorname{Var}\left(P_{i}\right)+\frac{1}{4} \cdot \operatorname{Var}\left(P_{i}\right)+2 \cdot \frac{1}{4} \cdot \operatorname{Cov}\left(P_{i}, P_{j}\right)
\end{aligned}
$$

Como $P_{i}$ e $P_{j}$, por hipótese, são observações da mesma população, temos que $\operatorname{Var}\left(P_{i}\right)=\operatorname{Var}\left(P_{j}\right)$. Portanto:

$$
\operatorname{Var}\left[\frac{P_{i}+P_{j}}{2}\right]=\frac{1}{2} \cdot \operatorname{Var}\left(P_{i}\right)+\operatorname{Cov}\left(P_{i}, P_{j}\right)
$$

Ou seja, vale a pena adotar uma média de dois se:

$$
\frac{1}{2} \cdot \operatorname{Var}\left(P_{i}\right)+\operatorname{Cov}\left(P_{i}, P_{j}\right)<\operatorname{Var}\left(P_{i}\right)
$$

Em que situações a adoção de médias mais longas é vantajosa? Claramente um dos casos é quando:

$$
\operatorname{Cov}\left(P_{i}, P_{j}\right)<0
$$

Intuitivamente o que a condição acima nos diz é que sempre que a inflação não tiver um caráter inercial, vale a pena adotar médias mais longas. Nesse caso, os choques de preços tendem a não se perpetuar no sistema. Por exemplo, uma alta da inflação causada pela alta do petróleo de USD 10 para USD 30 por barril deverá ser seguida por uma queda da inflação quando esse preços voltarem a um nível de equilíbrio.

Já no caso em que a covariância das inflações é positiva, nem sempre é benéfico utilizar médias mais longas para o inflation targeting. Nesse caso os choques podem tender a se perpetuar. No caso do nosso exemplo, uma inflação mais alta hoje por causa do aumento dos combustíveis pode tender a se perpetuar nos períodos seguintes. Dessa forma, adiar o combate da inflação logo no primeiro ano acaba gerando um problema maior no futuro. Como podemos inferir da fórmula (5) acima, existe um intervalo em que a despeito da covariância positiva entre as inflações, ainda vale a pena adotar média longas. Nesse caso, vale a pena adotar médias longas se:

$$
\operatorname{Cov}\left(P_{i}, P_{j}\right)<\frac{1}{2} . \operatorname{Var}\left(P_{i}\right)
$$

Essa característica interessante sugere que o arcabouço do inflation targeting no Brasil pode vir a incorporar uma política de combate prematuro do processo inflacionário. Por exemplo, para níveis baixos de inflação, quando a inércia infla- 
cionária tende a ser pequena, o Banco Central pode utilizar como target médias mais longas de inflação. Para taxas de inflação abaixo de 4\%, o Banco Central pode utilizar, uma média de 2 anos. (O nível de 4\% não é aleatório, correspondendo ao teto de tolerância associado a uma meta de inflação de $2,5 \%$, conforme será explicado nas conclusões). Isso, porém, ficaria condicionado a que a taxa acumulada em 12 meses não ultrapasse $6 \%$ (o referido limite mais metade do mesmo) em cujo caso a meta teria que voltar a ser fixada ponta-a-ponta.

Por uma questão talvez de maior facilidade de acompanhamento pela opinião pública, nos países que adotam metas de inflação o conceito monitorado de IPC — ou de "núcleo" - é a taxa de variação janeiro/dezembro. Entretanto, por analogia com o raciocínio empregado para calcular a inflação média do mês - em vez do critério "ponta-a-ponta" - seria conveniente examinar a hipótese de a variação do IPCA a ser estabelecida como meta levar em conta a variação do índice médio em 12 meses - isto é, comparação entre a média dos índices mensais de janeiro a dezembro de dois anos consecutivos — da mesma forma como ocorre com o IGP médio do ano.

O Gráfico 5 ajuda a entender a lógica do raciocínio. A inflação nos EUA aumentou no ano 2000 e no pico de variação a taxa em 12 meses chegou a ser de 3,7\%, embora a mínima tenha sido de $2,9 \%$. A taxa de 12 meses é, por definição, mais volátil que a taxa de variação da média de 12 meses contra a média dos 12 meses anteriores, que é uma espécie de média móvel mais longa das variações "ponta-aponta” em 12 meses. Se a taxa em 12 meses é volátil e por coincidência um dos momentos de pico ocorre no final do ano, uma política monetária essencialmente correta pode ser julgada um fracasso, por uma simples questão de calendário. ${ }^{15}$

Gráfico 5: CPI - EUA - Acumulado 12 meses vs. Média 12 meses/12 meses (\%)

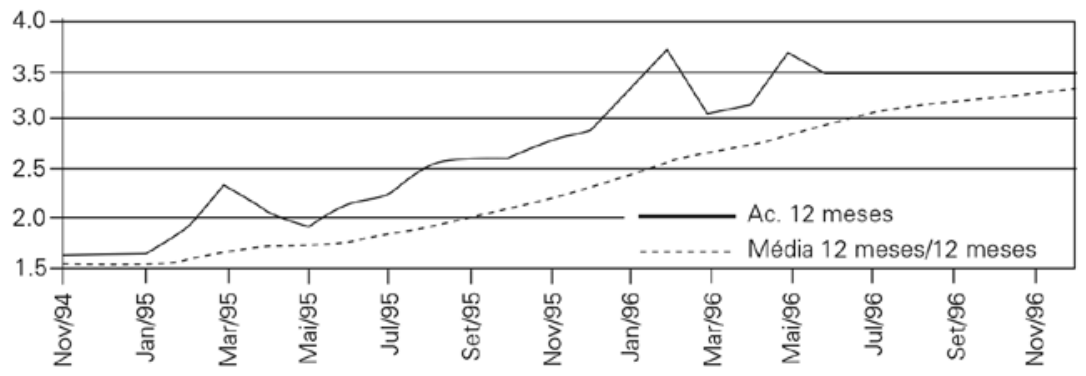

\footnotetext{
${ }^{15}$ Em termos econômicos, não há diferença alguma entre ter uma taxa acumulada em 12 meses de 2,8\% em setembro e de $3,2 \%$ em dezembro ou vice-versa, mas se o teto de um sistema de bandas de inflação for de $3,0 \%$, isso fará toda a diferença para as autoridades. Com um comprometimento baseado em médias de 12 meses - o que significa trabalhar com períodos móveis de 24 meses - as flutuações são suavizadas e evita-se o risco de que as autoridades sejam julgadas equivocadamente por eventuais desvios perfeitamente naturais em relação à meta.
} 
No caso do Brasil, observa-se um fenômeno parecido (Gráfico 6). Enquanto, depois da desvalorização de janeiro de 1999, a taxa de 12 meses chegou a um máximo de $8,9 \%$, a taxa máxima para o IPCA médio de $(\mathrm{t}+1)$ a $(\mathrm{t}+12)$ em relação à média de $(\mathrm{t}-11)$ a $\mathrm{t}$ foi de $7,3 \%$.

Gráfico 6: IPCA Brasil - Acumulado 12 meses vs. Média 12 meses/12 meses (\%)

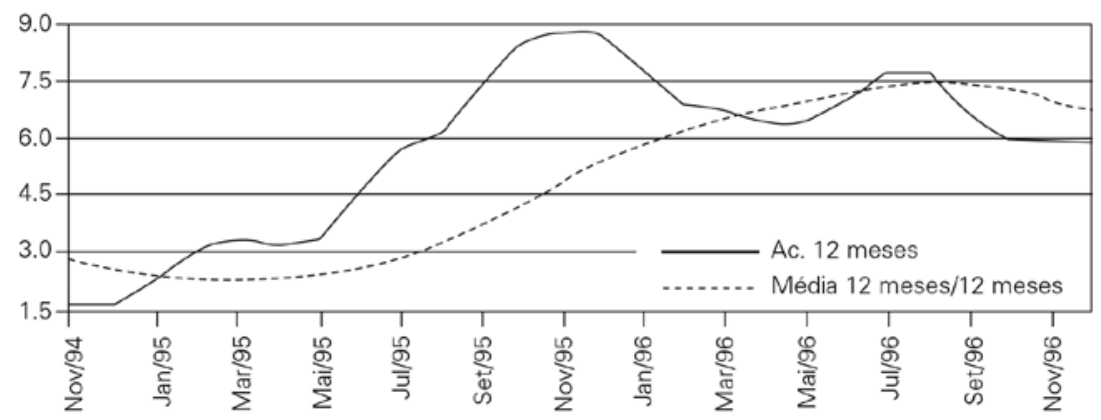

Fonte: IBGE

\section{CONCLUSÕES}

As sugestões feitas neste artigo visam reforçar o caminho da institucionalização da estabilização, que o Brasil começou a trilhar nos últimos anos, particularmente com a adoção, por um lado, de novos instrumentos legais, como a Lei de Responsabilidade Fiscal; e, de outro, do novo sistema de metas de inflação.

No ano em que este último sistema foi adotado, a taxa de inflação foi de quase $9,0 \%$ e o importante, naquelas circunstâncias, era recriar as condições para a verificação de uma trajetória declinante da inflação, o que foi conseguido com êxito, mediante a combinação de metas declinantes de inflação e uma política monetária ainda relativamente apertada. A mais de dois anos do início dessa experiência e com a meta de inflação até o final do governo estabelecida em 3,5\%, porém, é importante que se inicie um debate acerca de quais devem constituir as características de um regime "permanente" de metas de inflação, no sentido de ser mantido por tempo indefinido. O Brasil seguiria assim, embora "queimando etapas”, o caminho do Chile, que depois de vários anos de inflação declinante adotou recentemente uma regra de meta inflacionária por tempo indeterminado. ${ }^{16}$

Há várias vantagens de se adotar uma abordagem que poderia ser denominada de "institucionalista", como a que foi defendida no artigo. Em particular, cabe

\footnotetext{
${ }^{16}$ Esta é uma discussão aberta em outros países. Ver, por exemplo, o interessante artigo de Pierre Fortin em que ele propõe que o Canadá mude o seu regime de banda inflacionária de 1,0/3,0\% para 1,5/3,5\% (Fortin 2001, pág. 14)".
} 
destacar: a) a definição de um conjunto de regras diminuiria o espaço para a discrecionalidade das ações de Governo; b) a minimização, a exemplo do que ocorre nas economias estáveis, das chances de que, ocorrendo uma mudança de Governo, haja uma mudança drástica da política monetária; e c) a maior confiança dos agentes econômicos no enforcement do cumprimento da meta, pela possibilidade de sanções, hoje não previstas. Isto último, porém, só faria sentido se a figura de uma eventual punição ao presidente do Banco Central fosse a contrapartida de uma espécie de contrato institucional pelo qual à autoridade monetária fossem cobrados resultados, porém no contexto de uma independência operacional formal, da qual atualmente a instituição não dispõe.

Por outro lado, para evitar que se verifiquem equívocos na interpretação de eventuais desvios e que ocorram situações traumáticas como a sanção ao presidente do Banco Central em caso de descumprimento das metas por uma pequena margem, é necessário dotar o sistema de certa flexibilidade.

Sinteticamente, já definida a meta de inflação de 2003 em 3,25\%, propõe-se que a meta de inflação para 2004 e 2005 seja estabelecida em 3,0\% e 2,75\%, respectivamente; a de 2006, em 2,5\%; e que, levando em consideração o contexto de baixa inflação mundial, caso o mesmo persista, o Brasil adote o seguinte conjunto de regras permanentes para valer a partir de 2006, inclusive:

a) a adoção do IPCA médio núcleo ou core (média janeiro/dezembro vs. média janeiro/dezembro do ano anterior) como critério de inflação;

b) uma meta permanente do núcleo de inflação de 2,5\%, similar à taxa média de variação dos preços ao consumidor nos EUA nos últimos 5 anos;

c) um intervalo de tolerância de 1,5 ponto percentual acima e abaixo da meta, o que corresponde a um piso de $1,0 \%$ e a um teto de $4,0 \%$;

d) a condição de que a inflação acumulada em 12 meses não seja superior a6,0\%; sendo este teto ultrapassado a qualquer momento, o target passaria a ser a inflação janeiro/dezembro e a inflação janeiro/dezembro do ano posterior ao citado desvio não poderia ser superior a 4,0\%.

e) a possibilidade de demissão, nos termos legais a serem definidos, do presidente do Banco Central, caso a taxa de inflação média seja superior ao teto de $4,0 \%$ a.a. por dois anos consecutivos.

Se esse conjunto de regras for adotado e respeitado, aumentarão as chances de que o Brasil tenha, ao longo da década de 2000, uma taxa de variação dos preços similar à dos países da OECD, com claros benefícios em termos de eficiência econômica e bem-estar social, melhorando consideravelmente o ambiente para a adoção de decisões de investimento de longo prazo. 


\section{REFERÊNCIAS BIBLIOGRÁFICAS}

AGÉNOR, Pierre-Richard, "Monetary Policy under Flexible Exchange Rates - An Introduction to Inflation Targeting", The World Bank, Policy Research Working Paper, no. 2511, december.

BANCO CENTRAL (2000) Coletânea de Textos apresentados no seminário "Um ano de metas para a inflação", Banco Central, Rio de Janeiro, julho.

BLINDER, Alan (1998) Central Banking in Theory and Practice; The MIT Press.

CLIFTON, Eric (1999) "Inflation targeting: what is the meaning of the bottom of the band?"; IMF Policy Discussion Paper, PDP/99/8, december.

CONJUNTURA ECONÔMICA (2000) "O Plano Real, seis anos depois"; Carta do IBRE, junho. DELFIM NETTO, Antonio (1999) "Sobre as Metas Inflacionárias”; Economia Aplicada, 3 (3).

DORNBUSCH, Rudi (2000) "World economic trends"; Trans-National Research Corporation, august. EICHENGREEN, Barry (1996) Globalizing Capital - A History of the International Monetary System. Princeton University Press.

FORTIN, Pierre (2001) "Inflation targeting: the three percent solution"; Policy Matters, Institut for Research on Public Policy, Canada, February, vol. 2, n 1

FRAGA, Armínio (2000) "Regimes Cambiais e Monetários". Palestra apresentada em 27 de março de 2000 no IPEA; publicada com consentimento do palestrante, após transcrição, como texto Seminários DIMAC, número 6.

GIAMBIAGI, Fabio e RIGOLON, Francisco (1999) “A Atuação do Banco Central em uma Economia Estabilizada: é Desejável Adotar Metas Inflacionárias?”; Revista de Economia Política, 19(3), julho/ setembro.

LEIDERMAN, Leonardo e SVENSSON, Lars, eds (1995) Inflation Targets. Centre for Economic Policy Research-CEPR.

MISHKIN, Frederic (2000) "Inflation Targeting in Emerging Market Countries"; National Bureau of Economic Research-NBER, Working Paper 7618, march.

MISHKIN, Frederic (1999) “International Experiences with Different Monetary Policy Regimes"; National Bureau of Economic Research-NBER, Working Paper 7044, march.

PASTORE, Affonso Celso e PINOTTI, Maria Cristina (2000) "One Year of Inflation Targeting in Brazil: what have we learned about the channels of monetary transmission?"; trabalho apresentado no seminário seminário "Um ano de metas para a inflação", Banco Central, Rio de Janeiro, julho.

Secretaria de Política Econômica-SPE (1999) "Boletim de Acompanhamento Macroeconômico"; junho/ julho.

SVENSSON, Lars (1998) "Inflation targeting as a monetary policy rule"; National Bureau of Economic Research-NBER, Working Paper 6790, november.

WERLANG, Sérgio; BOGDANSKI, Joel e TOMBINI, Alexandre (2000) "Implementing inflation targeting in Brazil"; Banco Central do Brasil, Working Paper Series, número 1.

WORRELL, DeLisle (2000); "Monetary and Fiscal Coordination in Small Open Economies"; IMF Working Paper, WP/00/56, march. 